\title{
Solar thermal power generation
}

\author{
S P SUKHATME \\ Mechanical Engineering Department, Indian Institute of Technology, Powai \\ Bombay, 400 076, India
}

\begin{abstract}
The technologies and systems developed thus far for solar-thermal power generation and their approximate costs are described along with discussions for future prospects.
\end{abstract}

Keywords. Solar thermal energy; paraboloidal dish; parabolic collector technology; central receiver concept.

\section{Introduction}

The thermodynamic cycles used for solar thermal power generation can be broadly classified as low, medium and high temperature cycles. Low temperature cycles work at maximum temperatures of about $100^{\circ} \mathrm{C}$, medium temperature cycles work at maximum temperatures up to $400^{\circ} \mathrm{C}$, while high temperature cycles work at temperatures above $400^{\circ} \mathrm{C}$. Low temperature systems use flat-plate collectors or solar ponds for collecting solar energy. Recently, systems working on the solar chimney concept have been suggested. Medium temperature systems use the line focussing parabolic collector technology. High temperature systems use either paraboloidal dish collectors or central receivers located at the top of towers. In this paper, the technologies and systems developed thus far and their approximate costs are described.

\section{Low temperature systems}

A diagram of a typical low temperature system using flat-plate collectors and working on a Rankine cycle is shown in figure 1. The energy of the sun is collected by water flowing through the array of flat-plate collectors. In order to get the maximum possible temperature, booster mirrors which reflect radiation on to the flat-plate collectors are sometimes used. The hot water at temperatures close to $100^{\circ} \mathrm{C}$ is stored in a well insulated thermal storage tank. From here it flows through a vapour generator through which the working fluid of the Rankine cycle is also passed. The working fluid has a low boiling point. Consequently, vapour at about $90^{\circ} \mathrm{C}$ and a pressure of a few atmospheres leaves the vapour generator. This vapour then executes a regular Rankine cycle by flowing through a prime mover, a condenser and a liquid pump. The working fluids normally used are organic fluids like methyl chloride and toluene, and refrigerants like R-11, R-113 and R-114.

It has to be noted that the overall efficiency of this system is rather low, because the temperature difference between the vapour leaving the generator and the condensed liquid leaving the condenser is small. For the cycle shown in figure 1, the temperature difference is only $55^{\circ} \mathrm{C}$. This leads to a Rankine cycle efficiency of 7 to $8 \%$. The efficiency of the collector system is of the order of $25 \%$. Hence an overall efficiency of only about $2 \%$ is obtained. 


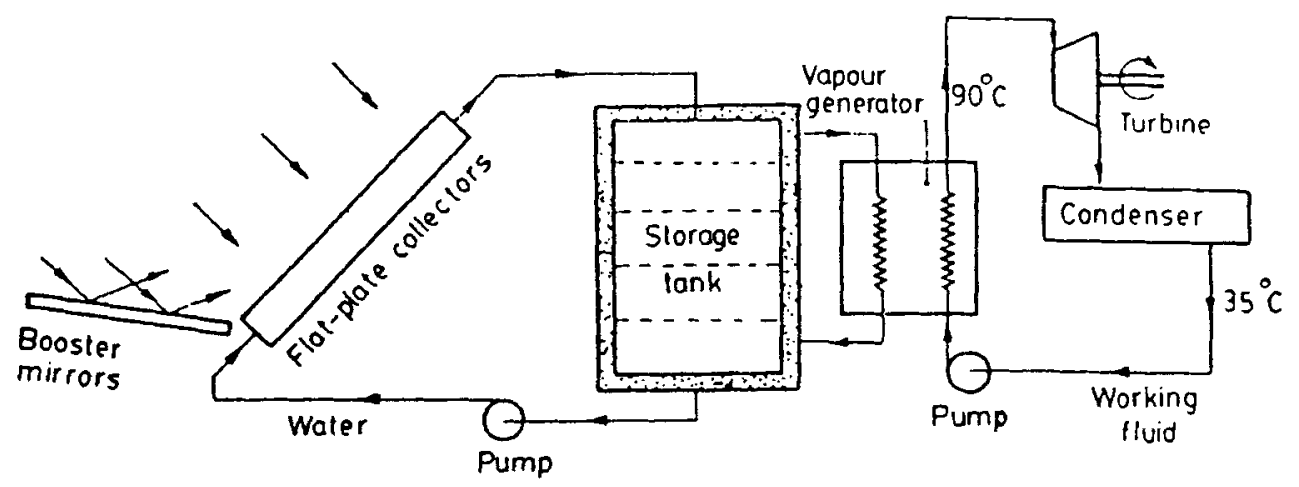

Figure 1. Low temperature power generation cycles using flat-plate collectors.

Plants of this type of French design having generation capacities up to about $50 \mathrm{~kW}$ were installed in many parts of the world, particularly Africa, in the seventies. A $10 \mathrm{~kW}$ plant was also installed at the Indian Institute of Technology Madras in 1979-80 under an Indo-German collaboration agreement. However, such piants have been found to be very costly because of the large collector areas involved. Typically, the installed cost is about Rs. 300000 per $\mathrm{kW}$ for 6 to $8 \mathrm{~h}$ of daily operation, the main component of cost being the collectors. Because of the low efficiency and high cost, this technology is now obsolete.

In order to reduce the cost, solar ponds have been used instead of flat-plate collectors. The first two solar pond power plants having capacities of $6 \mathrm{kWe}$ and $150 \mathrm{kWe}$ were constructed in Israel about 15 years ago. These were followed in 1984 by the Bet Ha-Arava power plant, the largest in the world with an area of $250000 \mathrm{~m}^{2}$ and a capacity of $5 \mathrm{MWe}$. The working of these plants has firmly established the technical viability of solar pond power plants. However they also do not appear to be economically attractive inspite of being less costly than plants using flat-plate collector systems.

Recently the concept of a solar chimney power plant has been suggested. In such a plant, a tall central chimney is surrounded at its base by a circular green-house consisting of a transparent cover supported a few metres above the ground by a metal frame (figure 2). Sunlight passing through the transparent cover causes the air trapped in the green-house to heat up. A convection system is set up in which this air is drawn up through the central chimney turning a trubine located near the base of the chimney. The hot air is continuously replenished by fresh air drawn in at the periphery of the green-house.

The only solar chimney power plant built so far is a $50 \mathrm{~kW}$ pilot plant in Spain. It has a $200 \mathrm{~m}$ high chimney with a constant diameter of $10.3 \mathrm{~m}$. The solar collector area extends to a radius of $126 \mathrm{~m}$ from the chimney with the glazing being $2 \mathrm{~m}$ above the ground. The turbine, housed at the base of the chimney, has four $5 \mathrm{~m}$ long blades and rotates at $1500 \mathrm{rpm}$ to produce an output of $50 \mathrm{~kW}$.

Although the energy conversion efficiency of such plants is low (of the order of $1 \%$ ), it is claimed that there will be considerable reduction in cost with scale-up and that a large size $1000 \mathrm{MW}$ piant may cost only $\$ 1000$ per $\mathrm{kW}$.

A large $200 \mathrm{MW}$ plant is currently being planned to be built in Jaisalmer, Rajasthan. The chimney for this plant will be $1000 \mathrm{~m}$ in height and will be built in stages, some power being generated at each stage. 
SOLAR

RADIATION
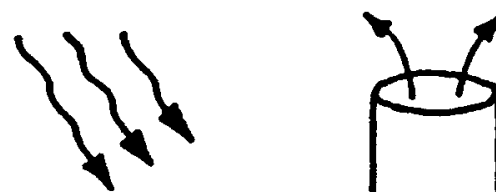

GLA Z ING

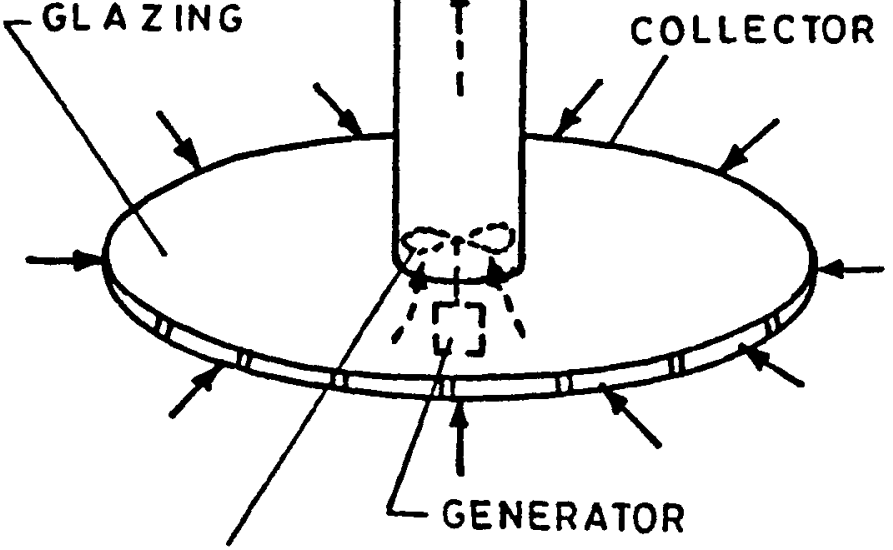

AIR TURBINE

Figure 2. Solar chemney power plant.

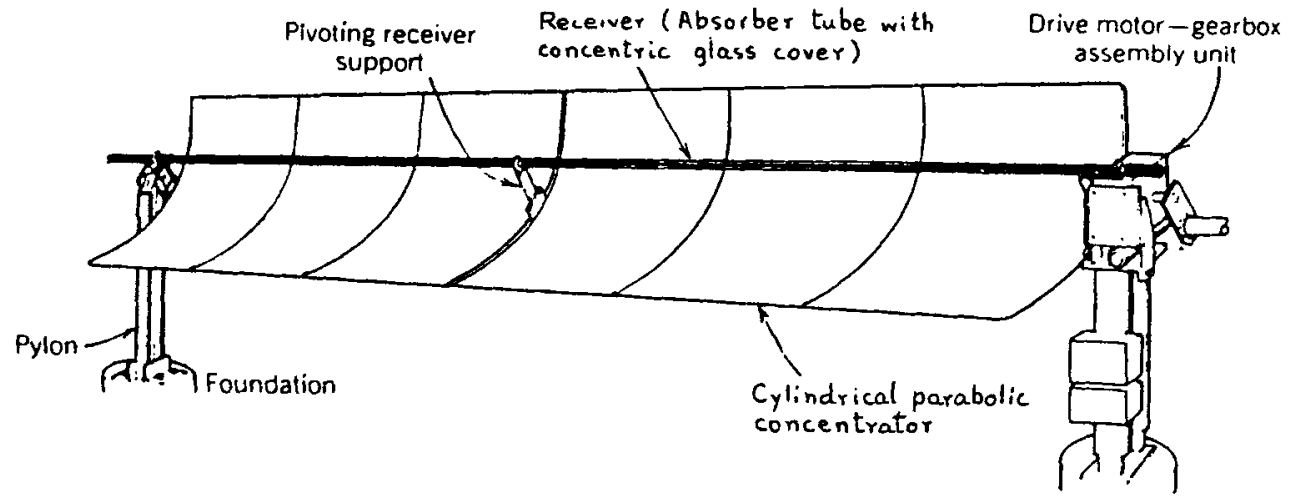

Figure 3. Cylindrical parabolic concentrating collector.

\section{Medium temperature systems}

Among solar thermal-electric power plants, those operating on medium temperature cycles and using line focussing parabolic collectors (figure 3 ) at a temperature of about $400^{\circ} \mathrm{C}$ have proved to be the most cost effective and successful so far. A schematic diagram of a typical plant is shown in figure 4 . The first commercial plant of this type having a capacity of $14 \mathrm{MW}$ was set up in 1984 . Since then, six plants of $30 \mathrm{MW}$ 


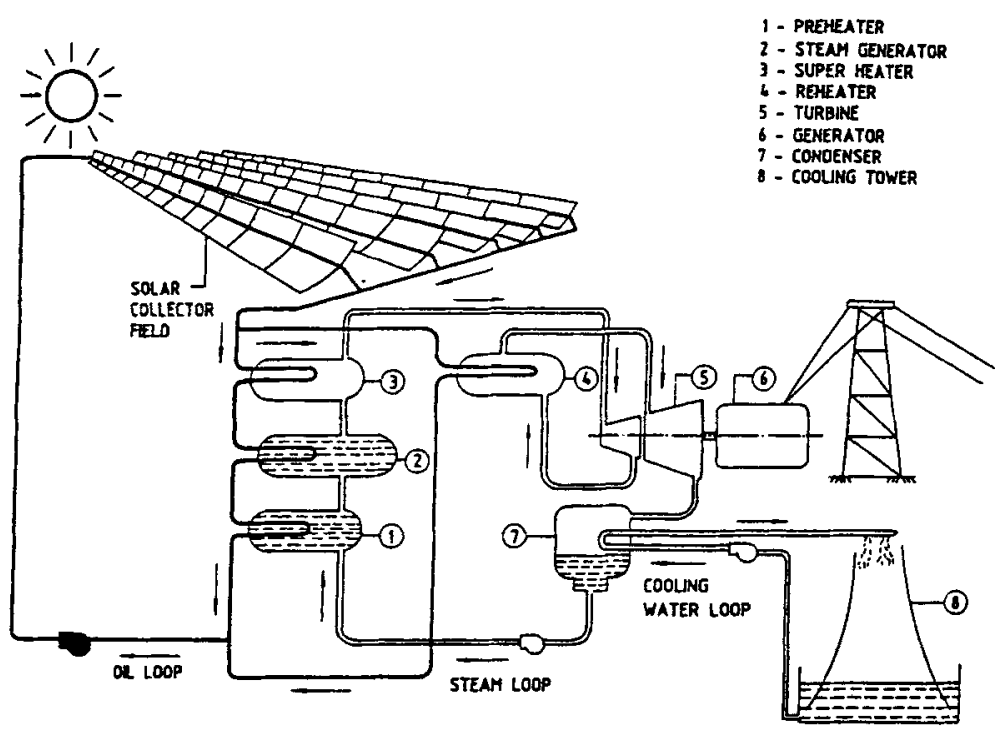

Figure 4. Medium temperature power generation cycle using parabolic concentrating collectors.

capacity each, followed by two plants of $80 \mathrm{MW}$ each have been installed and commissioned. All these plants have been set up by LUZ International in California, which has a total installed capacity of $354 \mathrm{MW}$. The collector array for the $80 \mathrm{MW}$ plant has an area of $464340 \mathrm{~m}^{2}$. The cylindrical parabolic collectors used have their axes oriented north-south. The absorber tube used is made of steel and has a specially developed selective surface. It is surrounded by a glass cover with a vacuum. The collectors heat a synthetic oil to a temperature of $400^{\circ} \mathrm{C}$ with a collector efficiency of about $0 \cdot 7$ for beam radiation. The synthetic oil is used for generating super-heated high pressure steam which executes a Rankine Cycle with an efficiency of $38 \%$. The plant generally produces electricity for about $8 \mathrm{~h}$ a day and is coupled with natural gas for continuous operation. The installed cost of this type of plant has reduced over the years because of the increasing installed capacity. The latest $80 \mathrm{MW}$ plant is reported to have cost $\$ .2900$ per $\mathrm{kW}$. The current generating cost is about 8 cents per $\mathrm{kWh}$.

The following are some details of the collector modules used in the $80 \mathrm{MW}$ power plant.

Aperture

Length

Reflecting surface

Reflectivity

Glass cover transmissivity

Vacuum in annular space

Absorber tube O. D.

Tube surface absorptivity

Tube surface emissivity

Optical efficiency

Peak collection efficiency

Annual collection efficiency
$5 \cdot 76 \mathrm{~m}$

$95 \cdot 2 \mathrm{~m}$

224 curved mirror glass panels

0.94

0.965

$10^{-4}$ torr

$0.070 \mathrm{~m}$

0.97

0.15

0.772

0.68 (based on beam radiation)

0.53 (based on beam radiation) 
The above data give some idea of the international state-of-the-art in line focussing cylindrical parabolic collector technology. It may be worth noting that such collectors are not yet being made commercially in India. However considerable expertise has been developed in constructing a number of prototypes in many research institutions.

The Indian experience with power generation using the line focussing parabolic collector technology has unfortunately been restricted so far only to a small $50 \mathrm{~kW}$ capacity experimental plant installed at the Solar Energy Centre of the Ministry of Non-Conventional Energy Sources. However, plans are underway for setting up a $35 \mathrm{MW}$ plant near Jodhpur. A detailed project report covering specifications of equipment and cost estimates has been prepared.

\section{High temperature systems}

Two concepts have been tried with high temperature systems. These are the paraboloidal dish concept and the central receiver concept.

\section{Paraboloidal dish collector system}

In the paraboloidal dish concept (figure 5) the concentrator tracks the sun by rotating about two axes and the sun's rays are brought to a point focus. A fluid flowing through

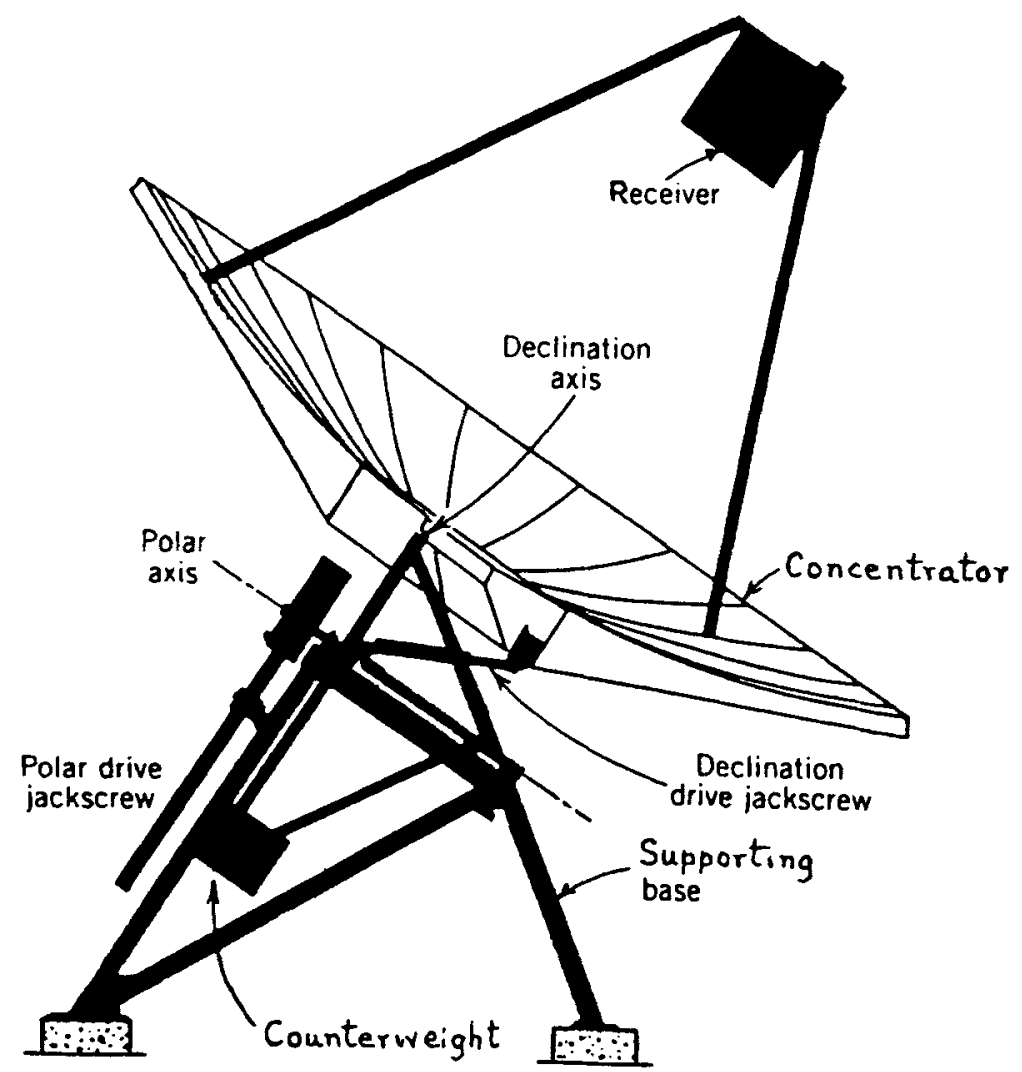

Figure 5. Paraboloid concentrating collector. 
a receiver at the focus is heated and this heat used to drive a prime mover. Typically Stirling engines have been favoured as the prime movers and systems having efficiencies upto $30 \%$ and generating power in the range of 8 to $50 \mathrm{~kW}$ have been developed. The Indian experience with this type of system has been restricted to a small experimental $20 \mathrm{~kW}$ power station near Hyderabad. Four paraboloidal dish collector modules were used to generate steam which ran a steam engine. Becuase of limitations on the size of the concentrator, paraboloidal dish systems can be expected to generate power in kilowatts rather than megawatts. Thus they can be expected to meet the local power needs of communities, particularly in rural areas.

Some commercial designs of paraboloid dish collector systems have been developed abroad in the last ten years for electric power production.

A $7.5 \mathrm{~m}$ diameter stretched metal membrane concentrator has been developed by a German firm. The membrane is a stainless steel sheet $(0.23 \mathrm{~mm}$ thick) fixed on both sides of a circular ring. The two membranes are deformed plastically to a parabolic shape by applying a water load and a partial vacuum, the vacuum being maintained during operation of the concentrator. The front membrane is covered with thin glass mirrors having a reflectivity of 0.90 and an area of $42 \mathrm{~m}^{2}$. The concentrator is suspended at two points in a polar mounting and tracks the sun by rotating daily about a vertical axis and seasonally about a horizontal axis. The focal length is $5 \mathrm{~m}$. A cavity-type receiver having a diameter of $0.2 \mathrm{~m}$ is kept at the focus. About $27 \mathrm{~kW}$ of energy is absorbed in the receiver if the incident beam radiation is $800 \mathrm{~W} / \mathrm{m}^{2}$. A Stirling engine located at the focus converts this thermal input to $8 \mathrm{kWe}$ with an energy conversion efficiency of 0.3 . More recently, the same firm has built two $17 \mathrm{~m}$ diameter dishes of the same design generating $50 \mathrm{~kW}$ each. These are in operation in Saudi Arabia. Dish/Stirling engine systems have also been built by other manufacturers.

As stated earlier. it is generally felt that paraboloid dish systems are best suited for applications which utilize solar energy directly at the focus of each collector. However in USA, a $5 \mathrm{MW}$ power plant utilizing the steam generated by seven hundred dishes has been erected. Each dish consists of a reflecting array of twentyfour $1.5 \mathrm{~m}$ diameter mirrors having an area of $42 \mathrm{~m}^{2}$. The mirrors are made of reflective polymeric film fixed on circular aluminium frames and subjected to a continuously applied vacuum. The receiver is an insulated cylindrical cavity about $0.9 \mathrm{~m}$ long and $0.6 \mathrm{~m}$ diameter and contains a molten sait. Pipes carrying water/steam pass through the salt bath. Thus the solar energy is first absorbed by the molten salt and then transferred to the water/steam, the salt bath acting as a storage which takes care of small variations in solar radiation.

Out of the total number of seven hundred dishes, six hundred are used to obtain saturated steam at $275^{\circ} \mathrm{C}$, while the remaining one hundred dishes are used to superheat the steam to $400^{\circ} \mathrm{C}$. The steam is used to run two turbine-generator sets-one a main set of $3.68 \mathrm{MW}$ and the other, a peaking set of $1.24 \mathrm{MW}$.

\section{Central receiver power plant}

In central receiver power plants; solar radiation reflected from arrays of large mirrors (called heliostats) is concentrated on a receiver situated at the top of a supporting tower. A fluid flowing through the receiver absorbs the concentrated radiation and transports it to the ground where it is used to operate a Rankine power cycle. A schematic diagram showing the main components of a central receiver power plant in which water is 


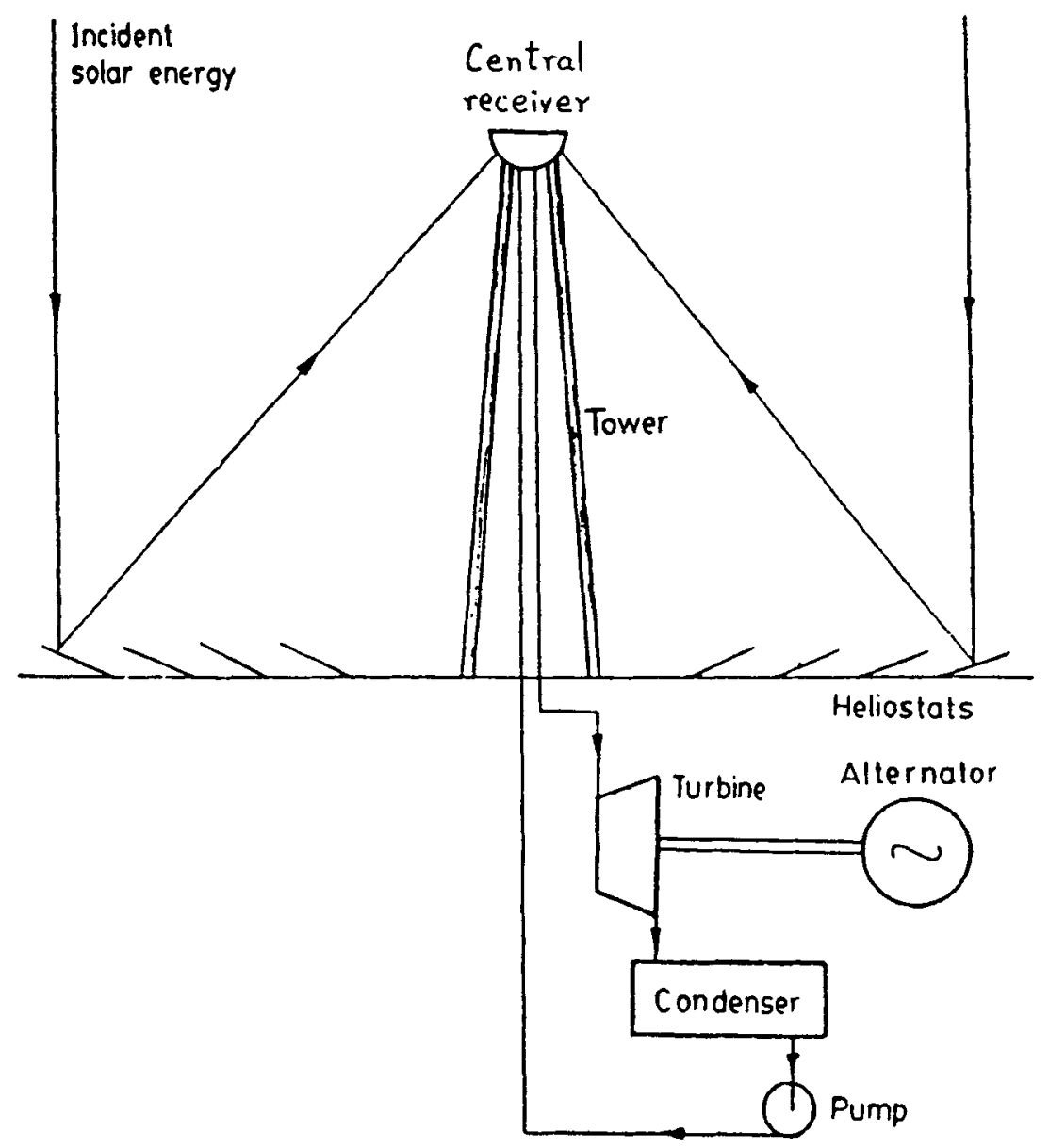

Figure 6. Central receiver power plant.

converted into steam in the receiver itself is shown in figure 6. Alternatively, the receiver is used to heat a liquid metal or a molten salt and this fluid is passed through a heat exchanger in which steam for the power cycle is generated.

The idea of building such a plant was first suggested by scientists in the Soviet Union. Based on their calculations, they indicated the possibility of erecting an installation in the sunny regions of the USSR to produce 11 to $13 \mathrm{t}$ of steam per hour at $30 \mathrm{~atm}$ and $400^{\circ} \mathrm{C}$. The optical system was calculated to consist of 1293 mirrors of $3 \times 5 \mathrm{~m}$. These heliostats were proposed to be mounted on carriages which moved on rails in arcs around the tower.

A number of small pilot plants were built in Italy in the period 1965 to 1967. In one of these $50 \mathrm{~kW}$ of energy was collected. After a break of a few years, the design of central receiver collector systems again attracted attention in the eighties and seven plants ranging in capacity from 0.5 to $10 \mathrm{MWe}$ were built. These are listed in table 1 along with some technical specifications. These include the number and the size of the heliostats, the receiver type, the receiver fluid and the height of the central supporting tower. 


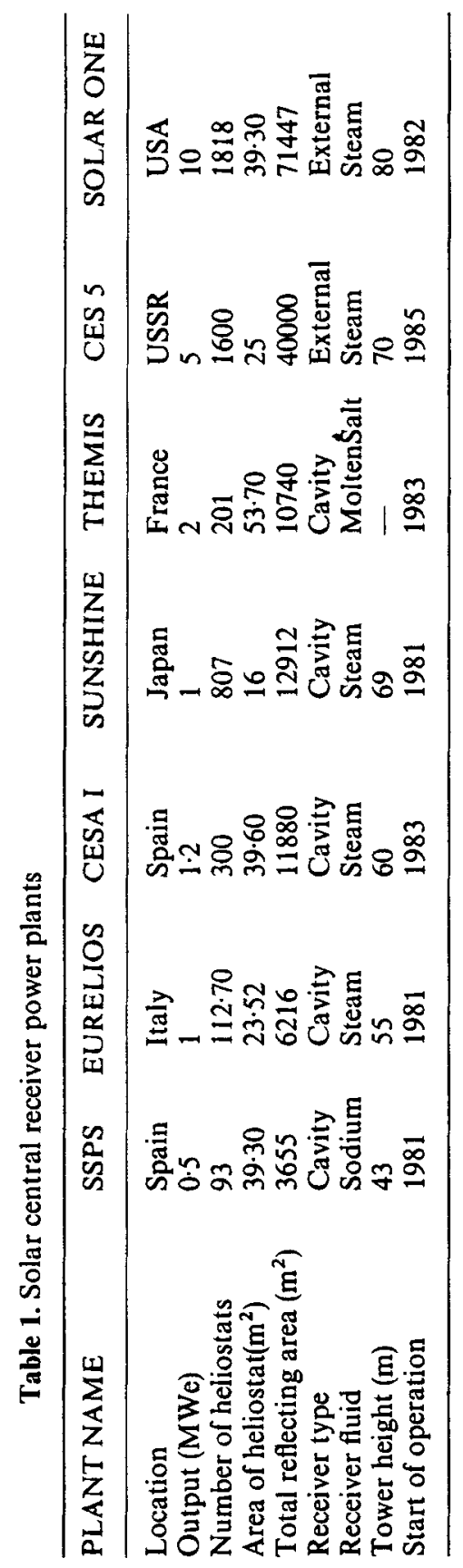


Although all the central receiver plants have been operated successfully, the available data indicate that the construction cost was very high. For example, the largest plant, Solar One, at Barstow, California cost approximately $\$ 14,000$ per $\mathrm{kW}$. However, costs are likely to reduce with more operational experience, improved design and scale-up.

The two major components requiring considerable development are the heliostats and the receiver. These will now be discussed.

The heliostats form an array of circular arcs around the central tower. They intercept, reflect and concentrate the solar radiation onto the receiver. The array is served by a tracking control system which continuously focusses beam radiation towards the receiver during collection. In addition, when solar radiation is not being collected, the control system orients the heliostats in a safe direction so that the receiver is not damaged.

As stated earlier, the $10 \mathrm{MWe}$ plant at Barstow was the largest of the pilot plants built. It was operated for six years from 1982 to 1988 . The plant had a field of 1818 heliostats positioned all round a central tower of height $80 \mathrm{~m}$. Each heliostat was an assembly of 12 slightly concave glass mirrors mounted on a support structure and geared drive that could be controlled for azimuth as well as elevation. The total refiective area of each heliostat was $39.3 \mathrm{~m}^{2}$. A rear view sketch is shown in figure 7 . The

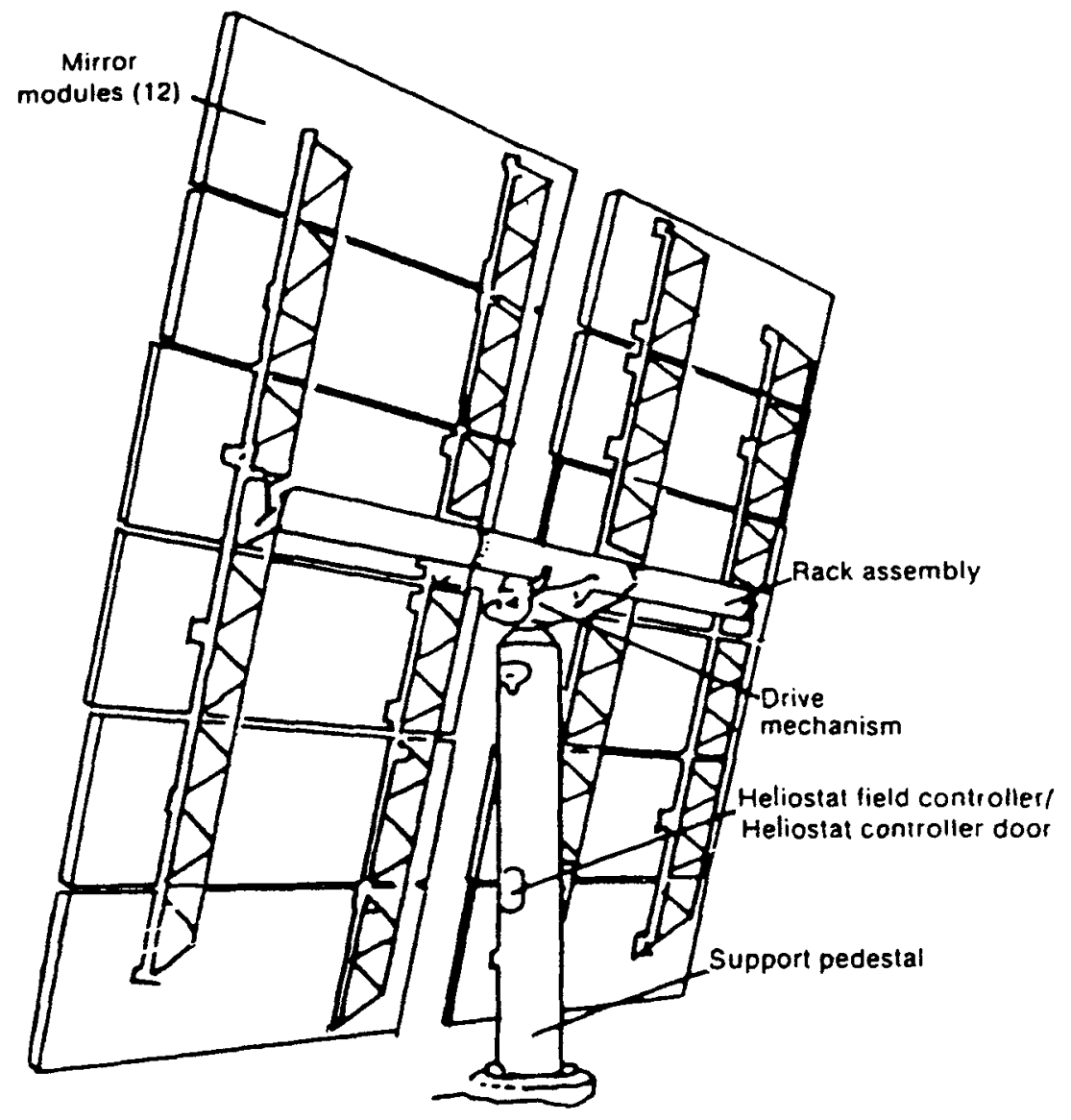

Figure 7. A heliostat. 
12 mirror panels in each heliostat were $1 \times 3 \mathrm{~m}$ in size and were made from $3 \mathrm{~mm}$ low iron float glass. When clean, the heliostats had an average reflectivity of 0.903 . However exposure to the environment caused them to become dirty, thereby reducing the average reflectivity to 0.82 . A goal of 0.92 has been set for future heliostat arrays. In order to achieve this goal along with reduced cost and weight, a number of new concepts are being tried. For example, larger size glass-mirror heliostats having areas of $150 \mathrm{~m}^{2}$ and reflectivity values up to 0.94 have been built. Also a new type of cost effective heliostat using a stretched membrane has been developed. In this heliostat, the reflector is a silvered polymer film laminated to a thin metal foil which is stretched over a large-diameter metal ring. The reflectivity of this surface has been measured to be 0.92 . Becuase of its simplicity and light weight, a stretched-membrane heliostat could be about $30 \%$ less costly than a glass-mirror design.

The receiver is the most complex part of the collection system. The main factor influencing its design is its ability to accept the large and variable heat flux which results from the concentration of the solar radiation by the heliostats. This flux has to be transferred to the receiver fluid. The value of the heat flux can range from 100 to $1000 \mathrm{~kW} / \mathrm{m}^{2}$ and this results in high temperatures, high thermal gradients and high stresses in the receiver. The value depends on the concentration ratio and varies with the season and the day. It also varies over the surface of the receiver. For these reasons, attention has to be given to the absorber shape, the heat transfer fluid, the arrangement of tubes to carry the fluid and the materials of construction.

There are two types of receiver designs: the external type and the cavity type (figure 8). The external receiver is usually cylindrical in shape. The solar flux is directed onto the outer surface of the cylinder consisting of a number of panels and is absorbed by the receiver fluid flowing through closely spaced tubes fixed on the inner side. On the other hand, in a cavity receiver, the solar flux enters through a small aperture in an insulated enclosure. The cavity contains a suitable tube configuration through which the receiver fluid flows. The geometry of the cavity is such that it maximises the absorption of the entering radiation, minimizes heat losses by convection and radiation to the ambient and at the same time accommodates the heat exchanger that transfers the radiant energy to the receiver fluid. Both types of receivers have their advantages and disadvantages. The external type has a very wide acceptance angle, while the cavity

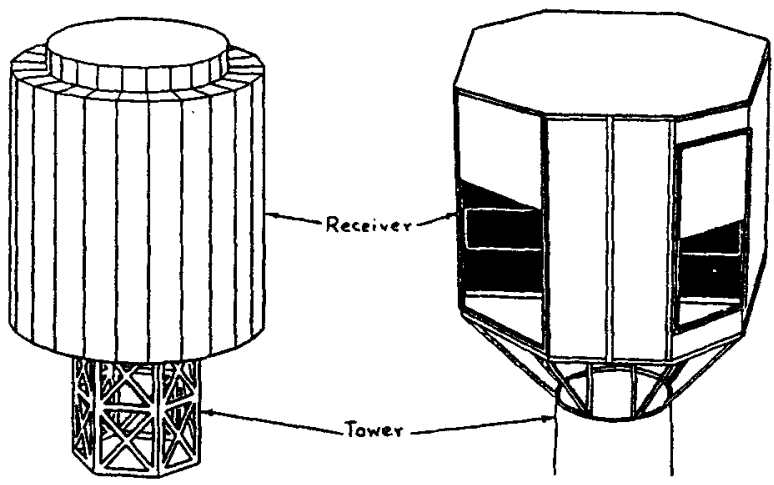

(a)

(b)

Figure 8. Receivers (a) External type, (b) Cavity type with four apertures. 
type has a small acceptance angle. On the other hand, the cavity type traps the solar flux more effectively and consequently has a higher efficiency than the external type. The 10 MWe plant at Barstow had an external type of receiver in which water was heated directly and converted to superheated steam. The receiver was a cylinder, $7 \mathrm{~m}$ in diameter and $13.5 \mathrm{~m}$ in height, made up of 24 vertical panels painted black. Incoloy 800 tubes $(0.6 \mathrm{~cm} \mathrm{I.} \mathrm{D.,} 1.25 \mathrm{~cm} \mathrm{O}$. D.) were fixed on the inside. The receiver was located on a tower $80 \mathrm{~m}$ high and produced steam at 102 bar and $510^{\circ} \mathrm{C}$. The receiver had an annual efficiency of 0.69 , which was rather low. In order to achieve higher efficiencies, it is planned that the next design will use a molten salt as the heat transfer fluid instead of water/steam. With a molten salt, the receiver can operate with higher incident solar fluxes. Consequently the size of the receiver would be reduced resulting in smaller thermal losses. In addition, the molten salt would be essentially at atmospheric pressure, thereby permitting the use of thinner walled tubes in the receiver. An annual efficiency goal of 0.90 has been set for this design.

\section{Conclusion}

Solar thermal energy can make a real impact if it leads to large scale cost-effective electrical power generation. The survey done in this paper shows that this is far from being the case. However, impressive developments have taken place in the last decade. Medium temperature systems using line focussing parabolic collector technology have been commercialized to some extent, the central receiver concept has been tested extensively on a pilot scale, and the solar chimney concept has been proved. The last two systems also show promise for commercialization, but need a considerable amount of developmental work. 